\title{
A COMPARISON OF THE CEPHALIN-CHOLESTEROL FLOCCULATION AND THYMOL TURBIDITY TESTS IN PATIENTS WITH EX- PERIMENTALLY INDUCED INFECTIOUS HEPATITIS ${ }^{1}$
}

\author{
By W. PAUL HAVENS, JR., AND RUTH E. MARCK \\ (From the Section of Preventive Medicine, Yale University School of Medicine, New Haven)
}

(Received for publication June 3, 1946)

The cephalin-cholesterol flocculation test $(1,2)$ and, more recently, the thymol turbidity test (3) have been widely used to determine the presence and degree of hepatocellular dysfunction in various diseases of the liver. The former is believed to depend on a qualitative change of the serum albumin, as well as a quantitative alteration in serum globulin (4). The latter is thought to be concerned with the formation of a globulin-thymol-lipid complex $(2,3)$. In a recent comparison of the results of these tests it has been suggested (5) that there may be an essential difference between their mechanisms, so that they cannot be used interchangeably. It is apparent that when strongly positive, both tests may be indicative of hepatocellular damage. Thus, both are equally useful in infectious hepatitis when the disease is well established, and during early convalescence. However, there are no serial data available on the comparative appearance times of positive tests, or their subsequent return to normal during the course of this disease. On the basis of the prior appearance of a positive cephalin-cholesterol flocculation test in 2 cases of subacute yellow atrophy, it has been suggested that this might be true of epidemic infectious hepatitis (5).

During the past 18 months, experiments conducted by the Neurotropic Virus Disease Commission on the transmission of infectious hepatitis to human volunteers have made it possible to study certain tests of liver function in such patients (6). It is the purpose of this paper to report on the results of the Hanger and the Maclagan tests in 27 patients during the incubation period and course of experimentally induced infectious hepatitis.

1 Representing work done for the Neurotropic Virus Disease Commission of the Board for the Investigation and Control of Influenza and Other Epidemic Diseases in the Army, in the Preventive Medicine Service of the Office of The Surgeon General, U. S. Army, Washington, D. C.

\section{METHODS AND MATERIALS}

Subjects. The subjects were previously healthy, male human volunteers, ranging in age from 19 to 29 years. These men contracted infectious hepatitis experimentally following inoculation or ingestion of material known to contain the etiologic agent of the disease. The diagnosis of infectious hepatitis was made on the basis of characteristic symptoms and signs accompanied by fever and consistent deflection of the bromsulphalein dye 2 (7) retention and cephalin-cholesterol flocculation (2) tests. All patients in this report had clinical jaundice.

Virus. The strain of virus used in this laboratory was originally obtained from the stool of a U. S. Army soldier (BE) who contracted epidemic infectious hepatitis in Sicily in 1943 (8). It has been through 4 passages in human volunteers to date. This agent is filtrable through an L2 Chamberland filter, and withstands heating to $56^{\circ} \mathrm{C}$. for at least 30 minutes (9). It has produced the disease in 27 out of 40 human volunteers (including those reported here) following parenteral or oral inoculation with incubation periods ranging from 15 to 34 days.

Laboratory observations. Four hundred cephalincholesterol flocculation tests, and 400 thymol turbidity tests were done on the sera of the 27 human volunteers. In practically all instances both tests were done on the same specimen of serum. Cephalin-cholesterol flocculation tests were performed according to the method of Hanger (2). Two different antigens ${ }^{3}$ were freshly prepared on each day of test, and duplicate tests were done on each serum. The maximum amount of flocculation regarded as normal was a trace in 24 hours, and 1 plus in 48 hours. All tests were done within 2 hours of obtaining serum from patients. When the 2 antigens did not agree in sensitivity, the test showing the lesser amount of flocculation was recorded. Thymol turbidity tests were done according to the method of Maclagan (3). The maximum normal turbidity was regarded as 1 to 4 units, as measured against the formazin standards 4 of Kingsbury et al (10). Most of these thymol turbidity tests were performed on freshly drawn sera, but a certain number were done on sera which had been frozen and stored at dry ice box temperature for periods ranging from 2 to 12 months. It had been previously determined

\footnotetext{
2 Retention of 10 per cent of dye 30 minutes after the intravenous injection of $5 \mathrm{mgm}$. of bromsulfalein per $\mathrm{kgm}$. of body weight was considered the maximum normal. 3 Obtained from Wilson and Co., Chicago, Ill.

4 Standard Reagents Co., Philadelphia, $\mathrm{Pa}$.
} 
that sera stored in such manner suffered no apparent change in their degree of reaction with the thymol reagent.

In the experiments to be reported here, the cephalincholesterol flocculation and thymol turbidity were determined at least twice in each subject before experimental inoculation. All were normal. After inoculation of the subjects with hepatitis virus, tests were done every 7 to 10 days until the onset of disease, when they were performed twice during the first week, and then every 10 days for the ensuing 2 months. During the 3rd month after onset each man was tested at least once.

\section{RESULTS}

When cephalin-cholesterol flocculation and thymol turbidity tests were performed this frequently, a regular pattern of response in infectious hepatitis was observed. Both tests became positive in a certain number of patients during the acute febrile phase of disease. The 27 patients reported here may be almost equally divided into 2 groups. One group had an acute onset of disease with fever. The other group had an insidious onset with vague abdominal symptoms for periods of 2 to 11 days before the appearance of fever. In general, it was observed that the 13 patients who made up the former group tended to develop positive cephalincholesterol flocculation and thymol turbidity tests during the first week (febrile period) of disease. In contrast, it was evident that the 14 patients in the latter group who had a vague onset with mild generalized abdominal complaints and a normal temperature, usually did not develop alteration in these tests until several days later after the appearance of fever.

By using the appearance of fever as a fixed point, it is possible to present the combined changes occurring in cephalin-cholesterol flocculation and thymol turbidity in all 27 patients of this series. When this is done, and the average duration of fever and jaundice and the appearance time of jaundice are recorded, it is seen that positive cephalin-cholesterol flocculation and thymol turbidity tests occur in a certain proportion of patients during the febrile phase before the appearance of jaundice, and that with defervescence and appearance of jaundice at the end of the 1st week of disease almost all patients tested had positive responses.

For purposes of convenience the results of cephalin-cholesterol flocculation and thymol turbidity tests are described as occurring in 4 phases; namely (1) the incubation (pre-febrile) phase, (2) the febrile (pre-icteric) phase, (3) the icteric (post-febrile) phase, and (4) the convalescent (post-icteric) phase.

Incubation (pre-febrile) phase.

When incubation periods were measured from the day of inoculation to the first appearance of symptoms they ranged from 15 to 28 days. However, the time elapsed from day of inoculation to onset of fever in these patients ranged from 24 to 30 days. Using the onset of fever as a fixed point, the results of the thymol turbidity and cephalincholesterol flocculation are recorded for 4 weeks before fever, and 3 months after fever, in 27 patients (Figure 1).

Thymol turbidity tests all remained normal throughout the incubation period, with the exception of one patient who had a single determination of 5 units 4 days before the onset of fever, when he was asymptomatic and when all other tests of liver function including the cephalin-cholesterol flocculation were normal.

The cephalin-cholesterol flocculations were normal during this period, with the exception of positive tests in 2 patients 1 and 3 days respectively before the onset of fever. Both of these patients were having gastrointestinal symptoms at the time, but all other tests of liver function were normal.

\section{Febrile (pre-icteric) phase.}

The duration of fever ranged from 4 to 14 days, averaging 8 days. Eighteen of the 27 patients had positive cephalin-cholesterol flocculation at some time during their febrile phase. During the first 2 days of fever most of the cephalin-cholesterol flocculation tests recorded were normal. From the 3rd day on, however, the preponderance of tests were positive.

Ten patients had positive thymol turbidity tests in their febrile phase. During the first 4 days of fever most of the thymol turbidity tests recorded were normal. The number of positive tests increased on the 5th day, and on the 6th and 7th days a preponderance of the tests were positive.

It is evident that the cephalin-cholesterol flocculation became positive significantly earlier than the thymol turbidity test. In Table I are recorded the results of these 2 tests during the febrile pe- 


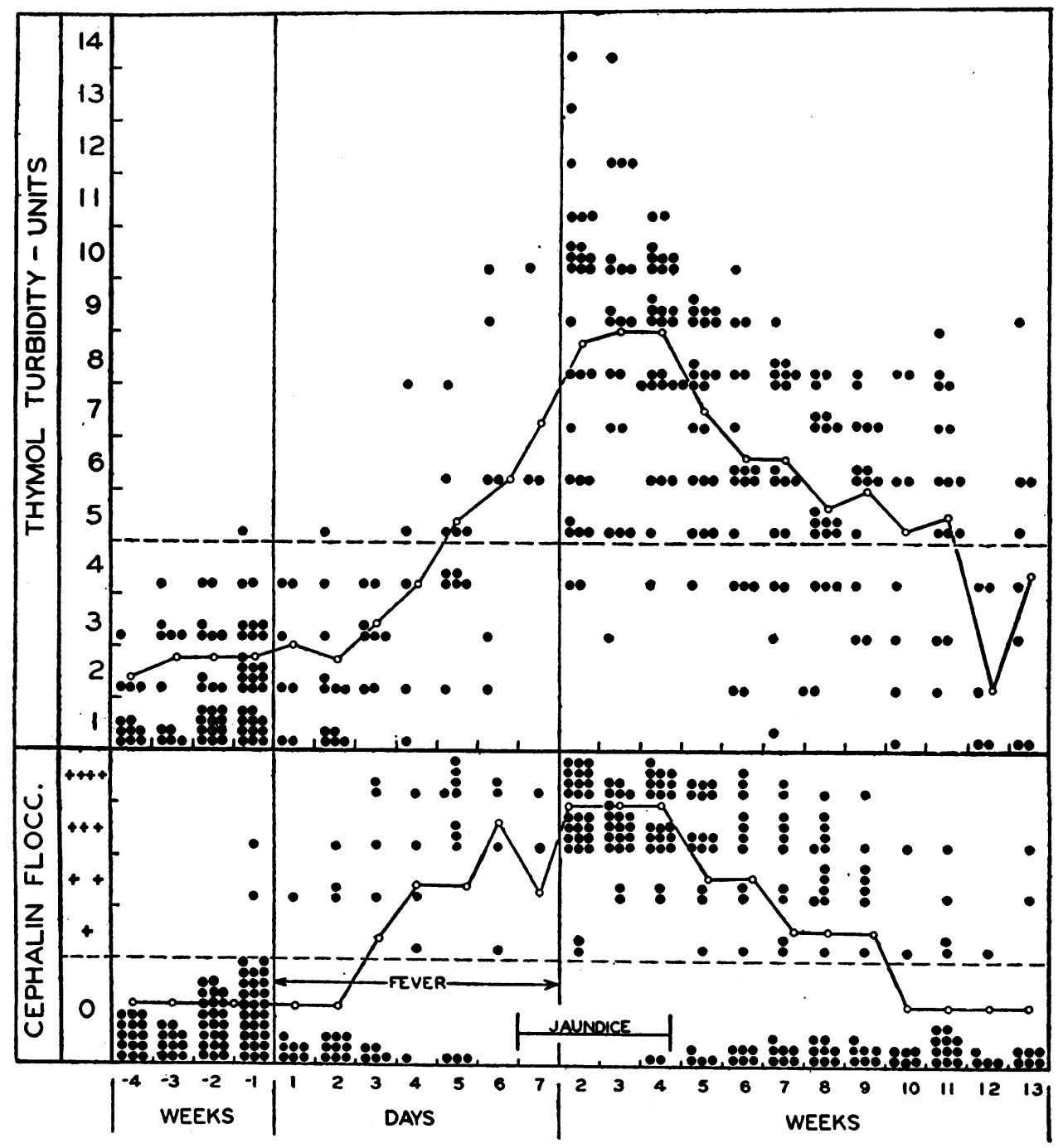

Fig. 1. Cephalin-cholesterol. Flocculation and Thymol Turbidity Tests in 27 Patients during the Incubation Period, Course of Disease, and Convalescence of ExpertMeNTALly Induced Infectious Hepatitis

$(-)$ indicates weeks before the onset of fever. Black dots indicate individual determinations which are expressed as an average by the unbroken lines. The duration of fever and jaundice and the appearance time of jaundice represent the averaged experiences of the 27 patients. The horizontal (broken) lines indicate the normal maximum level of cephalin-cholesterol flocculation and thymol turbidity tests.

riod. In the first 5 days of fever before the appearance of jaundice, 20 out of 45 sera had positive cephalin-cholesterol flocculations, while only 8 out of 43 of these sera had positive thymol turbidity tests. Attention is called to the fact that a certain number of patients had their 2 sets of tests within the first 4 days of fever. In view of the greatly increased percentage of positive tests in the last 3 days of the febrile period, it is quite possible that had all patients been tested at this time a greater number might have been positive.

\section{Icteric (post-febrile) phase.}

Clinical jaundice ranged in appearance from 3 to 12 days after the beginning of fever, averaging 6 days. The duration of jaundice ranged from 8 
TABLE I

Cephalin-cholesterol flocculation and thymol turbidity tests in patients with experimentally induced infectious hepatitis

\begin{tabular}{|c|c|c|c|c|}
\hline \multirow{2}{*}{$\begin{array}{l}\text { Day of } \\
\text { fever }\end{array}$} & \multicolumn{2}{|c|}{ Cephalin flocculation } & \multicolumn{2}{|c|}{ Thymol turbidity } \\
\hline & Tested & Positive & Tested & Positive \\
\hline & \multicolumn{4}{|c|}{ number of sera } \\
\hline $\begin{array}{l}1 \\
2 \\
3 \\
4 \\
5 \\
6 \\
7 \\
8\end{array}$ & $\begin{array}{r}8 \\
12 \\
9 \\
5 \\
11 \\
4 \\
2 \\
6\end{array}$ & $\begin{array}{l}1 \\
3 \\
4 \\
4 \\
8 \\
4 \\
2 \\
6\end{array}$ & $\begin{array}{r}7 \\
12 \\
8 \\
5 \\
11 \\
6 \\
3 \\
8\end{array}$ & $\begin{array}{l}0 \\
1 \\
0 \\
2 \\
5 \\
4 \\
3 \\
7\end{array}$ \\
\hline Total & 57 & 32 & 60 & 22 \\
\hline
\end{tabular}

to 31 days, with an average of 20 days. Characteristically clinical jaundice appears with defervescence at the end of the first week. The cephalin-cholesterol flocculation and thymol turbidity tests were positive at some time during the icteric phase of all patients, with the exception of one who was mildly sick and failed to develop positive thymol turbidity, although other tests of liver function were positive. During the 2nd week of disease, as clinical jaundice increased, the cephalincholesterol flocculation and thymol turbidity tests with rare exceptions were strongly positive. This continued throughout the period of jaundice, through the 4th week of disease.

\section{Convalescent (post-icteric) phase.}

During the 5th week of disease the cephalincholesterol flocculation remained positive in general, and it is not until the 6th week that the number of negative tests increased materially. During the 7th, 8th, and 9th weeks of disease the cephalin-cholesterol flocculation became less positive in many patients, and the number of negatives increased so that by the 10th week the average of tests was within normal range, although from there through the 13th week an occasional patient had a positive test. During the period of observation, 20 patients had a return to negative cephalin-cholesterol flocculation. The duration of positive tests in these patients ranged from 25 to 87 days, with an average of 53 days. Seven patients still had mildly positive tests at the last time of observation, ranging from 77 to 172 days after onset of disease.

From the 5 th week of disease the degree of positivity of the thymol turbidity tests was less
TABLE II

Disagreement in results of cephalin-cholester ol flocculation and thymol turbidity tests in 23 patients with experimentally induced infectious hepatitis

\begin{tabular}{|c|c|c|c|}
\hline $\begin{array}{l}\text { Week after } \\
\text { fever }\end{array}$ & $\begin{array}{l}\text { Thymol } \\
\text { turbidity }\end{array}$ & \multicolumn{2}{|c|}{$\begin{array}{l}\text { Cephalin-cholesterol } \\
\text { flocculation }\end{array}$} \\
\hline-1 & $\begin{array}{c}\text { units } \\
5 \\
2 \\
2\end{array}$ & $\begin{array}{l}24 \text { hours } \\
0 \\
++ \\
+++\end{array}$ & $\begin{array}{l}48 \text { hours } \\
0 \\
+++ \\
++++\end{array}$ \\
\hline 1 & $\begin{array}{l}4 \\
2 \\
2 \\
3 \\
3 \\
4 \\
2 \\
4 \\
1 \\
2 \\
6 \\
4 \\
4 \\
4 \\
4 \\
3\end{array}$ & $\begin{array}{l}++ \\
0 \\
+++ \\
++ \\
++++ \\
++++ \\
+++ \\
++ \\
+ \\
+++ \\
0 \\
+++ \\
++++ \\
++++ \\
++++ \\
\pm\end{array}$ & $\begin{array}{l}+++ \\
++ \\
++++ \\
+++ \\
++++ \\
++++ \\
++++ \\
+++ \\
++ \\
++++ \\
+ \\
++++ \\
++++ \\
++++ \\
++++ \\
++\end{array}$ \\
\hline 2 & $\begin{array}{l}4 \\
4\end{array}$ & $\begin{array}{l}++t+ \\
++\end{array}$ & $\begin{array}{l}+t+t \\
+t\end{array}$ \\
\hline 3 & 3 & ++ & $+t+$ \\
\hline 4 & 6 & 0 & 0 \\
\hline 5 & $\begin{array}{l}9 \\
9 \\
5\end{array}$ & $\begin{array}{l}0 \\
0 \\
0\end{array}$ & $\begin{array}{l}0 \\
+ \\
0\end{array}$ \\
\hline 6 & $\begin{array}{l}4 \\
8 \\
6\end{array}$ & $\begin{array}{l}+ \\
0 \\
0\end{array}$ & $\begin{array}{l}++ \\
0 \\
0\end{array}$ \\
\hline 7 & $\begin{array}{l}8 \\
5 \\
8\end{array}$ & $\begin{array}{l}\mathbf{0} \\
0 \\
0\end{array}$ & $\begin{array}{l}0 \\
+ \\
0\end{array}$ \\
\hline 8 & $\begin{array}{l}5 \\
5 \\
7\end{array}$ & $\begin{array}{l}\mathbf{0} \\
\mathbf{0} \\
\mathbf{0}\end{array}$ & $\begin{array}{l}\mathbf{0} \\
\mathbf{0} \\
\mathbf{0}\end{array}$ \\
\hline 9 & $\begin{array}{l}6 \\
8 \\
7 \\
7 \\
6\end{array}$ & $\begin{array}{l}\mathbf{0} \\
\mathbf{0} \\
\mathbf{0} \\
\mathbf{0} \\
\mathbf{0}\end{array}$ & $\begin{array}{l}+ \\
0 \\
0 \\
0 \\
0\end{array}$ \\
\hline 10 & $\begin{array}{l}6 \\
8 \\
4 \\
6\end{array}$ & $\begin{array}{l}0 \\
0 \\
+ \\
0\end{array}$ & $\begin{array}{l}0 \\
0 \\
++ \\
0\end{array}$ \\
\hline 11 & $\begin{array}{l}6 \\
8 \\
6 \\
6 \\
5 \\
8 \\
5\end{array}$ & $\begin{array}{l}\mathbf{0} \\
\mathbf{0} \\
\mathbf{0} \\
\mathbf{0} \\
\mathbf{0} \\
\mathbf{0} \\
\mathbf{0}\end{array}$ & $\begin{array}{l}\mathbf{0} \\
\mathbf{0} \\
\mathbf{0} \\
\mathbf{0} \\
\mathbf{0} \\
\mathbf{0} \\
\mathbf{0}\end{array}$ \\
\hline 12 & 4 & + & ++ \\
\hline 13 & $\begin{array}{l}5 \\
6\end{array}$ & $\begin{array}{l}\mathbf{0} \\
\mathbf{0}\end{array}$ & $\begin{array}{l}\mathbf{0} \\
\mathbf{0}\end{array}$ \\
\hline
\end{tabular}

$(-)$ before fever 
strong, and a gradually increasing number of patients fell within the normal range, so that by the 12th week the average determination of thymol turbidity was normal, although several patients continued to have positive tests. Only 14 of 26 patients had a return to normal thymol turbidity during the period of observation. The duration of positive tests in these patients ranged from 30 to 112 days, with an average of 64 days. Twelve patients still had mildly positive tests at the last time of observation, ranging from 75 to 172 days.

Agreement of tests. In 23 of the 27 patients with experimentally induced infectious hepatitis there was qualitative lack of agreement in the results of the cephalin-cholesterol flocculation and thymol turbidity tests at some time during the period of observation, extending from the day of inoculation through convalescence. This occurred 60 times in a total of 360 simultaneous tests (16 per cent). In Table II are recorded the results of these tests for 13 weeks. The preponderance of early disagreement occurred in the first 5 days of the febrile, and was dependent on the fact that the cephalin-cholesterol flocculation became positive earlier than the thymol turbidity test. From the end of the first week until the middle of the 4th week there was almost complete agreement of tests qualitatively, with the exception of rare negative thymol turbidity in the presence of positive cephalin-cholesterol flocculation. After the 4th week, however, there appeared a gradually increasing number of tests which failed to agree in positivity. In contrast, however, the failure of agreement at this time was dependent on the persistence of positive thymol turbidity tests in patients whose cephalin-cholesterol flocculations had returned to normal. Wide quantitative variation in degree of positivity in the 2 tests occurred, and there appeared to be little correlation between them except in the active early icteric phase of disease, when both tests were strongly positive in almost all patients.

\section{DISCUSSION}

It has been pointed out in this paper that the cephalin-cholesterol flocculation test becomes positive at a significantly earlier period than the thymol turbidity test in experimentally induced infectious hepatitis. In agreement with the results of others, both tests are of equal value when the disease is well established, and at this time there is almost complete agreement in positivity between them both qualitatively and quantitatively. However, early in disease in the pre-icteric period, and late in the convalescent period, disagreement in positivity occurs in a regular pattern. This is dependent on the fact that the cephalincholesterol flocculation becomes positive earlier than the thymol turbidity and returns to normal before the latter test. The fact that this type of disagreement occurred in 23 out of 27 patients at some time during the course of their infectious hepatitis lends support to the suggestion of other investigators $(5,11)$ that the mechanism of the 2 tests may not be the same, and therefore they cannot be used interchangeably. The significantly greater proportion of positive cephalin-cholesterol flocculation tests in comparison with thymol turbidity tests in the first 5 days of the febrile phase of infectious hepatitis makes the former test of greater value in early diagnosis. At present, it is difficult to interpret the prognostic significance of the fact that the thymol turbidity remains positive longer in convalescence than the cephalincholesterol flocculation. It is not known whether this may represent activity of hepatitis or the persistence of some biologic change upon which the mechanism of the test is dependent (12).

\section{SUMMARY}

1. The results of serial determinations of the cephalin-cholesterol flocculation and thymol turbidity tests in patients during the incubation period and course of disease of experimentally induced infectious hepatitis are presented.

2. With rare exceptions both tests were negative during the incubation period, but became positive in all patients at some time during the course of disease, with the exception of one man with mild illness who had a normal thymol turbidity in the presence of other positive evidence of liver dysfunction.

3. Although both tests were equally positive in the active icteric phase of disease, the cephalincholesterol flocculation became positive earlier than the thymol turbidity test, and also returned to normal before the latter test.

4. The disagreement in positivity between the cephalin-cholesterol flocculation test and the thy- 
mol turbidity test early in the pre-icteric phase and late in the convalescent phase lends support to the concept that their mechanisms may be different.

Acknowledgment is made of the assistance and cooperation of the following agencies: Selective Service, Camp Operations Division: Civilian Public Service Unit. No. 68; Civilian Public Service Unit No. 81; Civilian Public Service Unit No. 140; the Connecticut State Hospital, Middletown, Connecticut; the Norwich State Hospital, Norwich, Connecticut; the Federal Correctional Institution, Danbury, Connecticut; and the U. S. Public Health Service.

\section{BIBLIOGRAPHY}

1. Hanger, F. M., The flocculation of cephalin-cholesterol emulsions by pathological sera. Tr. A. Am. Physicians, 1938, 53, 148.

2. Hanger, F. M., Serological differentiation of obstructive from hepatogenous jaundice by flocculation of cephalin-cholesterol emulsions. J. Clin. Invest., 1939, 18, 261.

3. Maclagan, N. F., Thymol turbidity test: A new indicator of liver dysfunction. Nature, London, 1944, 154, 670.

4. Moore, D. B., Pierson, P. S., Hanger, F. M., and Moore, D. H., Mechanism of the positive cephalincholesterol flocculation reaction in hepatitis. J. Clin. Invest., 1945, 24, 292.

5. Watson, C. J., and Rappaport, E. M., A comparison of the results obtained with the Hanger cephalincholesterol flocculation test and the Maclagan thy- mol turbidity test in patients with liver disease. J. Lab. and Clin. Med., 1945, 30, 983.

6. Drill, V. A., Changes in liver function during experimentally induced human hepatitis. Yale J. Biol. and Med., 1946, 18, 345.

7. Rosenthal, S. M., and White, E. C., Clinical application of the bromsulphalein test for hepatic function. J. A. M. A., 1925, 84, 1112.

8. Havens, W. P., Jr., Ward, R., Drill, V. A., and Paul, J. R., Experimental production of hepatitis by feeding icterogenic materials. Proc. Soc. Exp. Biol. and Med., 1944, 57, 206.

9. Havens, W. P., Jr., Properties of the etiologic agent of infectious hepatitis. Proc. Soc. Exp. Biol. and Med., 1945, 58, 203.

10. Kingsbury, F. B., Clark, C. P., Williams, G., and Post, A. L., The rapid determination of albumin in the urine. J. Lab. and Clin. Med., 1926, 11, 981.

11. Recant, L., Chargaff, E., and Hanger F. M., Comparison of the cephalin-cholesterol flocculation test with the thymol turbidity test. Proc. Soc. Exp. Biol. and Med., 1945, 60, 245.

12. Kunkel, H. G., and Hoagland, C. L., Persistence of elevated values for the thymol turbidity test following infectious hepatitis. Proc. Soc. Exp. Biol. and Med., 1946, 62, 258.

After this manuscript was submitted for publication a similar persistence of positive thymol turbidity in the presence of negative cephalin-cholesterol flocculation tests was described in patients with infectious hepatitis. (Neefe, J. R., Results of hepatic tests in chronic hepatitis without jaundice. Gastroenterology, 1946, 7, 1.) 